\title{
Optic nerve hypoplasia, encephalopathy, and neurodevelopmental handicap
}

\author{
John P Burke, Michael O’Keefe, Roger Bowell
}

\begin{abstract}
Abnormalities of the central nervous system are frequently described in optic nerve hypoplasia. In a longitudinal study of 46 consecutive children (32 term, 14 preterm) with bilateral optic nerve hypoplasia $32(69.5 \%)$ had associated neurodevelopmental handicap. Of these, $90 \%$ had structural central nervous system abnormalities on computed tomographic brain scans. Neurodevelopmental handicap occurred in $62.5 \%$ of the term and $86 \%$ of the preterm infants respectively. Term infants had a greater incidence of ventral developmental midline defects and proportionately fewer maternal and/or neonatal complications throughout pregnancy, while encephaloclastic lesions were commoner among the premature infants. An association of optic nerve hypoplasia with the twin transfusion syndrome and prenatal vascular encephalopathies is described.
\end{abstract}

Optic nerve hypoplasia is a non-progressive congenital abnormality of multifactorial aetiology. Its pathogenesis is not fully understood, but it may follow a variety of insults to any part of the developing visual pathways..$^{1-3}$ It is a major cause of visual loss in childhood and may be associated with important central nervous system and endocrine abnormalities, ${ }^{4-11}$ which include septo-optico dysplasia, porencephaly, encephalocele, congenital suprasellar tumours, hypothyroidism, diabetes insipidus, growth hormone deficiency, and many others. These have recently been the subject of a minireview. ${ }^{12}$ The increasing numbers of children described with this abnormality may reflect increased awareness on the part of ophthalmologists as well as an increase in its prevalence.

In contrast to some earlier reports, neurodevelopmental handicaps are being increasingly recognised in association with optic nerve hypoplasia, though their prevalence in and interrelationship with this anomaly have not been fully established. We serially assessed 46 cases of bilateral optic nerve hypoplasia, 32 of which had neurodevelopmental handicap. We examined the factors involved in the simultaneous occurrence of both conditions and describe the association of this anomaly with vascular encephalopathies, in particular the twin transfusion syndrome. ${ }^{13}$

\section{Patients and methods}

The study population consisted of 46 consecutive children with bilateral optic nerve hypoplasia who attended the Paediatric Ophthalmology Department of the Children's Hospital, Temple
Street, Dublin, from 1985 to 1989 . Physical and neurological examinations showed that 32 children (18 males, 14 females) had variable degrees of neurodevelopmental handicap, of which mental retardation, cerebral palsy, and epilepsy were the commonest. The diagnosis of optic nerve hypoplasia was made or confirmed by two of us (MOK, RB) based on a combination of characteristic features. These included (1) a small optic nerve head, (2) a double pigmentary ring sign, and (3) an abnormal nerve fibre layer. ${ }^{14}$ Various objective means of confirming the diagnosis can be used, ${ }^{715}$ as the ophthalmoscopic diagnosis in milder cases may be difficult. However, these tests would have required greater patient co-operation than most children in this study could have provided.

Each child underwent a detailed ophthalmic examination. A history was obtained from the case records and from parents or guardians. This included gestational age, obstetric history, maternal medical history, and prenatal, perinatal, and postnatal complications. The referral pattern for each patient was documented. Visual acuity was estimated by ocular motor fixation patterns, forced choice preferential looking, and Sheridan and Gardiner or Snellen acuity testing. Appropriate tests were selected on the basis of the patient's age and level of co-operation

Most of the children were examined by computed tomographic (CT) brain or magnetic resonance imaging scans, electroretinography and pattern stimulation, or diffuse light visual evoked responses. A paediatrician and/or paediatric neurologist examined each child before or within three months of their initial ophthalmic assessment.

\section{Results}

Children with optic nerve hypoplasia and neurodevelopmental handicap were divided into three groups. There were 12 children in group 1 (Table 1) with bilateral optic nerve hypoplasia and neurodevelopmental handicap who were born prematurely and 20 children in group 2 (Table 2) with bilateral optic nerve hypoplasia and neurodevelopmental handicap who were born at or after 37 weeks gestation. There were 14 children in group 3 with bilateral optic nerve hypoplasia who had no neurodevelopmental handicap.

All children in group 1 (Table 1) were born between the 26th and 33rd week, and when last seen their ages ranged from 9 to 56 months. All had been initially referred by paediatricians for visual assessment. Three had been delivered by emergency caesarian section, one for failure to progress in the second stage of labour and two for fetal distress. Four children were products of 
Table 1 Clinical findings in 12 children with bilateral optic nerve hypoplasia and neurodevelopmental handicap born prematurely ( $\leqslant 36$ weeks gestation)

\begin{tabular}{|c|c|c|c|c|}
\hline $\begin{array}{l}\text { Patient/ } \\
\text { gestational age } \\
\text { (weeks) }\end{array}$ & Birth history & $\begin{array}{l}\text { Pre-and } \\
\text { perinatal history }\end{array}$ & $C T$ or $M R I$ diagnosis & $\begin{array}{l}\text { Associated } \\
\text { fundus findings }\end{array}$ \\
\hline $1 / 28$ & \multirow{2}{*}{$\begin{array}{l}\text { Assisted breech } \\
\text { delivery } \\
\text { SVD }\end{array}$} & $\begin{array}{l}\text { Severe RDS } \\
\text { GMH-IVH }\end{array}$ & Porencephaly & - \\
\hline $2 / 26$ & & $\begin{array}{l}\text { Severe RDS } \\
\text { GMH-IVH }\end{array}$ & CPVL & Regressed ROP \\
\hline \multirow[t]{2}{*}{$3 / 30$} & SVD & PET and APH & \multirow{2}{*}{$\begin{array}{l}\text { Diffuse cerebral and } \\
\text { cerebellar atrophy }\end{array}$} & \multirow[t]{2}{*}{ Atrophic discs } \\
\hline & TTS & $\begin{array}{l}\text { Apnoea of } \\
\text { prematurity }\end{array}$ & & \\
\hline $4 / 30$ & CS & $\begin{array}{l}\text { Severe RDS } \\
\text { GMH-IVH }\end{array}$ & $\begin{array}{l}\text { Suprasellar arachnoid cyst } \\
\text { with hydrocephalus }\end{array}$ & - \\
\hline $5 / 32$ & $\begin{array}{l}\text { SVD } \\
\text { TTS }\end{array}$ & Severe RDS & $\begin{array}{l}\text { CPVL } \\
\text { Diffuse cerebral atrophy }\end{array}$ & Atrophic discs \\
\hline $6 / 30$ & SVD & $\begin{array}{l}\text { Severe RDS } \\
\text { GMH-IVH }\end{array}$ & CPVL & - \\
\hline $7 / 30$ & $\begin{array}{l}\text { SVD } \\
\text { twin }\end{array}$ & $\begin{array}{l}\text { Severe RDS } \\
\text { GMH-IVH }\end{array}$ & CPVL cerebral atrophy & - \\
\hline $\begin{array}{l}8 / 30 \\
9 / 33\end{array}$ & $\begin{array}{l}\mathrm{CS} \\
\mathrm{CS}\end{array}$ & $\begin{array}{l}\text { Maternal anaemia } \\
\text { Severe PET }\end{array}$ & $\begin{array}{l}\text { CPVL cerebral atrophy } \\
\text { Normal }\end{array}$ & - \\
\hline $10 / 27$ & SVD & RDS GMH-IVH & Diffuse cerebral atrophy & Regressed ROP \\
\hline $11 / 28$ & $\begin{array}{l}\text { Placenta } \\
\text { praevia }\end{array}$ & RDS GMH-IVH & & Regressed ROP \\
\hline $12 / 27$ & SVD & RDS GMH-IVH & Diffuse cerebral atrophy & Regressed ROP \\
\hline
\end{tabular}

$\mathrm{CT}=$ computed tomographic brain scan $. \mathrm{MRI}=$ magnetic resonance imaging scan $. \mathrm{RDS}=$ respiratory distress syndrome. GMH-IVH = germinal matrix haemorrhage - intraventricular haemorrhage. distress syndrome. GMH-IVH = germinal matrix haemorrhage - intraventricular haemort
ROP = retinopathy of prematurity. SVD = spontaneous vaginal delivery. CPVL=cystic

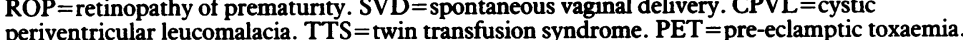
periventricular leucomalacia. TTS $=$ twin transfusion syndrome. $P E T=$ pre-eclamptic toxaemia
$\mathrm{APH}=$ antepartum haemorrhage $. \mathrm{CS}=$ caesarian section. $\mathrm{SLE}=$ systemic lupus erythematosus.

twin pregnancies, and two of these suffered from twin transfusion syndrome. Maternal complications included severe pre-eclampsia in two cases, active systemic lupus erythematosus in one, and maternal anaemia of $7.5 \mathrm{~g} / \mathrm{dl}$ in one mother who initially presented some days before going into spontaneous labour at 30 weeks gestation. There was no history of maternal diabetes mellitus. All 12 infants had a complicated perinatal/neonatal period.

Most recent visual acuities ranged from apparently normal to no visual fixation. The

Table 2 Clinical findings in 20 children with bilateral optic nerve hypoplasia and neurodevelopmental handicap born at or after 37 weeks gestation

\begin{tabular}{|c|c|c|c|c|}
\hline Patient no & Birth history & $\begin{array}{l}\text { Pre-and } \\
\text { perinatal } \\
\text { complications }\end{array}$ & $C T$ or $M R I$ diagnosis & $\begin{array}{l}\text { Associated } \\
\text { fundus findings }\end{array}$ \\
\hline 13 & SVD & - & Agenesis, corpus callosum & - \\
\hline 14 & SVD & - & Agenesis, corpus callosum & - \\
\hline 15 & SVD & - & Agenesis, corpus callosum & - \\
\hline 16 & SVD & $\begin{array}{c}\text { Suspected IUT } \\
\text { infection }\end{array}$ & Agenesis, corpus callosum & - \\
\hline 17 & SVD & - & $\begin{array}{l}\text { Agenesis, corpus callosum, } \\
\text { congenital hydrocephalus, } \\
\text { diffuse cerebral atrophy }\end{array}$ & Atrophic discs \\
\hline 18 & SVD & $\begin{array}{l}\text { Postnatal } \\
\text { encephalopathic } \\
\text { illness }\end{array}$ & $\begin{array}{l}\text { Agenesis, corpus callosum, } \\
\text { diffuse cerebral atrophy }\end{array}$ & - \\
\hline 19 & SVD & - & $\begin{array}{l}\text { Agenesis, corpus callosum, } \\
\text { Joubert's syndrome }\end{array}$ & $\begin{array}{l}\text { Pigmentary } \\
\text { retinopathy }\end{array}$ \\
\hline 20 & SVD & - & Agenesis, corpus callosum & \\
\hline 21 & SVD & $\begin{array}{l}\text { TTS } \\
\text { HIE }\end{array}$ & $\begin{array}{l}\text { Schizencephaly, diffuse } \\
\text { cerebral atrophy }\end{array}$ & Atrophic discs \\
\hline 22 & SVD & - & $\begin{array}{l}\text { Aqueduct stenosis, } \\
\text { hydrocephalus }\end{array}$ & Atrophic discs \\
\hline 23 & SVD & $\begin{array}{l}\text { Familial } \\
\text { neurodegenerative } \\
\text { disorder }\end{array}$ & Diffuse cerebral atrophy & Atrophic discs \\
\hline 24 & SVD & $\begin{array}{l}\text { Intrauterine } \\
\mathrm{CMV} \text { infection }\end{array}$ & Schizencephaly & Atrophic discs \\
\hline $\begin{array}{l}25 \\
26\end{array}$ & $\begin{array}{l}\text { SVD } \\
\text { SVD }\end{array}$ & $\begin{array}{l}- \\
-\end{array}$ & $\begin{array}{l}\text { Diffuse cerebral atrophy } \\
\text { Normal }\end{array}$ & $\begin{array}{l}\text { Pigmentary } \\
\text { retinopathy }\end{array}$ \\
\hline $\begin{array}{l}27 \\
28\end{array}$ & $\begin{array}{l}\text { SVD } \\
\text { SVD }\end{array}$ & $\begin{array}{l}- \\
-\end{array}$ & $\begin{array}{l}\text { Holoprosencephaly } \\
\text { Porencephaly, diffuse } \\
\text { cerebral atrophy }\end{array}$ & Atrophic discs \\
\hline $\begin{array}{l}29 \\
30\end{array}$ & $\begin{array}{l}\text { SVD } \\
\text { SVD }\end{array}$ & - & $\begin{array}{l}\text { Congenital hydrocephalus } \\
\text { Holoprosencephaly }\end{array}$ & $\overline{\text { Atrophic discs }}$ \\
\hline 31 & SVD & $\begin{array}{l}\text { Birth } \\
\text { Asphyxia }\end{array}$ & $\begin{array}{l}\text { Congenital hydrocephalus } \\
\text { Dandy-Walker syndrome }\end{array}$ & - \\
\hline 32 & SVD & - & Congenital hydrocephalus & - \\
\hline
\end{tabular}

$\mathrm{CT}=$ computed tomographic brain scan. $\mathrm{MRI}=$ magnetic resonance imaging scan . SVD = spontaneous vaginal delivery. IUT $=$ intrauterine. $T$ TS $=$ twin transfusion syndrome. $\mathrm{HIE}=$ hypoxia ischaemic encephalopathy. $\mathrm{CMV}=$ cytomegalovirus. amplitude of the binocular flash visual evoked potential correlated better with the visual acuity than did the latent interval. ${ }^{16}$ There were six cases with a visual acuity of $\leqslant 6 / 60$ (cases $2,3,8$, $9,10,12)$, three cases with an acuity of $\geqslant 6 / 9$ (cases $1,6,7$ ), and three (cases $4,5,11$ ) with intermediate levels. Other ocular abnormalities observed were bilateral optic disc pallor in two cases, presumed cortical visual loss in three, and regressed retinopathy of prematurity in four.

All 12 children had cerebral ultrasound and/or computed tomographic brain (CT) scans performed. Periventricular haemorrhage was visible in six cases by ultrasonography in the neonatal period. One child (case 9) had a normal CT scan. The other 11 scans showed either diffuse cerebral atrophy and/or other encephaloclastic lesions of the developing brain (Table 2). The latter arise from the destruction of previously formed cerebral tissue by a vascular insult. There were no isolated anterior midline developmental defects.

There were 20 children in group 2 (Table 2). When they were last seen their ages ranged from 13 to 80 months. All were referred by paediatricians because of suspected visual handicap. There was no history of maternal diabetes mellitus. Eighteen births were uncomplicated. One mother with twins had an emergency forceps delivery for failure to progress in the second stage of labour (case 21), and one infant had perinatal asphyxia in association with meconium aspiration. Five infants had congenital hydrocephalus and one had cranial diabetes insipidus. An intrauterine infection was suspected in three children (cases 16, 24, 26), though unproved in two. The third had cytomegalovirus isolated from her urine three days postnatally (case 24). Eight infants had agenesis of the corpus callosum on CT scan. In addition, three of these had primary and one (case 18) had secondary microcephaly.

Visual acuities ranged from probably normal to no visual fixation. The amplitude of the binocular flash visual evoked potential correlated better with the visual acuities than the latent interval. There were three cases with acuities of $\geqslant 6 / 9$ (cases $15,25,26$ ), one with an acuity of $6 / 12$ (case 20), and the remainder with acuities of $\leqslant$ $6 / 60$. Seven cases had optic disc pallor in association with hypoplastic discs.

There were 14 children with no evidence of neurodevelopmental handicap when assessed (group 3). Three were born before 32 weeks and the remainder after 36 weeks gestation. There was no maternal history of diabetes mellitus or epilepsy. Two of the premature infants were initially referred by paediatricians for retinopathy of prematurity (ROP) screening. One had bilateral optic nerve hypoplasia in association with mild ROP, while the other, who was born to a mother with pre-eclamptic toxaemia, had isolated optic nerve hypoplasia, and thin optic nerves were subsequently identified on CT scan. The third infant was referred at 5 months with early onset esotropia. Of the 11 children born after 36 weeks gestation five were referred by paediatricians with suspected visual handicap. The diagnoses of the referred patients included oculocutaneous albinism, fetal alcohol effects, 
dysmorphic syndrome, postencephalopathic illness, and nystagmus secondary to isolated optic nerve hypoplasia. Six children were referred by their family practitioner. Of these two had albinism, three presented with strabismus, and one had nystagmus, an alternating esotropia, bilateral optic nerve hypoplasia, and a normal CT scan. None of the 46 children studied had tumours of visual pathways. ${ }^{6}$

\section{Discussion}

Optic nerve hypoplasia is not a specific disease but a morphological diagnosis which may result from damage at any location in the developing visual pathways. ${ }^{17}$ Likewise the location of the injury to the developing brain, causing neurodevelopmental handicap, may vary in accordance with the time in utero when the fetus was exposed to the insult, while its sequelae may or may not be visible on CT scan. This may explain why intrauterine insults sufficiemt to produce neurodevelopmental handicap may also result in optic nerve hypoplasia.

Skarf and Hoyt ${ }^{18}$ noted that delayed development was the most frequently associated nonvisual complication. Nineteen of 41 children (46\%) with symmetrical bilateral optic nerve hypoplasia had developmental delay. Margalith et $a l^{19}$ noted neuropsychiatric handicaps in $72.6 \%$ of 51 patients ( $92 \%$ bilateral), of which mental retardation (70.6\%) and cerebral palsy (56.9\%) were the most frequent. Edwards and Layden ${ }^{20}$ described a series of 14 cases of bilateral optic nerve hypoplasia of which seven had evidence of cerebral palsy and/or mental handicap. Neuroradiological abnormalities were detected in $61 \%$ of the 93 patients with bilateral optic nerve hypoplasia in these three series. The results differed from those of earlier studies, as Walton and Robb ${ }^{21}$ reported on 20 patients with optic nerve hypoplasia ( 12 bilateral) who enjoyed normal growth and development, while Acers $^{22}$ commented on the infrequent association of optic nerve hypoplasia with mental and/or physical handicap among a series of 45 cases (40 bilateral). In our series $69.5 \%$ of 46 cases had neurodevelopmental handicap, and $90 \%$ of these had neuroradiological abnormalities. Our database was selective in that 40 of the 46 children were referred by paediatricans for screening or with suspected visual handicap.

It was possible to divide the neurodevelopmentally handicapped children into two groups on the basis of gestational age. There were 12 cases born prematurely and 20 born after 36 weeks gestation. We, like Margalith et a ${ }^{19}$ found the prevalence of perinatal/neonatal and maternal complications to be substantially higher among infants born prematurely. Four of the 12 premature children also had regressed retinopathy of prematurity and germinal matrix-intraventicular haemorrrhages. Brown et al ${ }^{23}$ observed a positive correlation between retinopathy of prematurity and intraventricular haemorrhage in premature infants, while others ${ }^{24} 25$ have suggested that severe retinopathy of prematurity and periventricular leucomalacia may both be associated with episodes of cerebrovascular insufficiency. We suggest that the simultaneous occurrence of optic nerve hypoplasia in such patients may imply a contributory ischaemic basis for all three events. To our knowledge no study exists which examines the link, if any, between retinopathy of prematurity and optic nerve hypoplasia.

Ventral developmental midline defects occurred exclusively in the chidren born at or near term. These represent anomalies in closure of the anterior neural tube, and severe defects may be associated with epilepsy and mental/ physical retardation of variable severity. ${ }^{26}$ Seven of eight cases in this series with agenesis of the corpus callosum, optic nerve hypoplasia, and neurodevelopmental handicap were products of apparently normal pregnancies. The aetiology of optic nerve hypoplasia in a number of the other 12 cases was unknown (Table 2). One infant (case 24) had intrauterine cytomegalovirus infection. The significance of this association, which was previously reported by Hittner $e t a l$, is unclear. ${ }^{27}$

Congenital hydrocephalus has been infrequently described in association with optic nerve hypoplasia, ${ }^{8192122}$ Ghose $^{28}$ did not describe any case in a series of 200 patients with hydrocephalus. We noted five children born at term with congenital hydrocephalus and optic nerve hypoplasia (four obstructive, one communicating). One of these had the Dandy-Walker syndrome, which is frequently associated with other central nervous system abnormalities. One must assume that either optic nerve hypoplasia predated and is unrelated to the hydrocephalus, or that optic nerve hypoplasia can result from this defect, occurring some time prior to the full development of the visual system.

Likewise the simultaneous occurrence of optic nerve hypoplasia and optic atrophy is being recognised with increasing frequency, ${ }^{1819}$ while the difficulty in differentiating one from the other in some cases may be owing to an insult to the near completely developed visual pathways. ${ }^{1}$ The fact that some believe that hypoplastic discs may be pale or normal in colour further confuses diagnostic interpretation in young children. ${ }^{29}$ Margalith et $a l^{19}$ described 47 patients with bilateral optic nerve hypoplasia, $16 \%$ of whom had associated optic atrophy, while nine of 32 patients (28\%) in this series had coexisting optic atrophy.

The pathogenesis of encephalopathy and encephaloclastic lesions in the developing brain is diverse and rarely demonstrable. ${ }^{217}$ Periventricular haemorrhage, which is usually preceded by cerebral ischaemia, ${ }^{30}$ was identified in six of the 12 cases born prematurely. Functional disorders of perfusion such as ischaemia from placental abruption, toxaemia (cases three and nine), or transient vasculitis (case 4) may play a part. Other postulated aetiologies include deficient maternal nutrition (case 8) and anomalies of placental development. To our knowledge the twin transfusion syndrome (cases $3,5,21$ ) has not been previously described in association with optic nerve hypoplasia. It was Benirschke ${ }^{31}$ who first implicated the death of a monozygotic twin as a potential cause for problems in the surviving twin as a consequence of disseminated intravascular coagulation or from emboli from the 
deceased cotwin entering the circulation of the survivor. Melnick ${ }^{32}$ subsequently stated that $1 \%$ of monozygotic twin births have severe brain defects as a consequence of the foregoing mechanisms. They and others ${ }^{13}$ described surviving infants with porencephaly and/or hydrencephaly who were usually severely mentally retarded with microcephaly, spastic diplegia, and seizures.

Optic nerve hypoplasia, particularly if bilateral, may be associated with a large variety of ocular and systemic abnormalities. The selection of patients referred to ophthalmic departments can undoubtedly lead to bias. However, the comparison of our findings with other published series allows further insight into the spectrum of optic nerve hypoplasia. Good visual acuity $(\geqslant 6 / 9)$ was present in a minority (6 of 32 ) of children, while normal CT scans may be found in cases with visual, mental, and physical handicap, indicating the diverse and unpredictable findings that have come to be expected with this anomaly.$^{33}$ We confirmed the general impression that bilateral optic nerve hypoplasia is associated with neurodevelopmental handicap in a considerable percentage of affected term and preterm infants, while the occurrence of optic nerve hypoplasia and hypoxic-ischaemic brain injury in premature infants with or without associated retinopathy of prematurity may suggest common underlying links and merits further study. Similarly, the temporal relationship and significance of coexisting optic nerve hypoplasia and atrophy needs further elucidation.

All children with bilateral optic nerve hypoplasia, and in particular those with impaired vision and suspected neurodevelopmental handicap, should be considered for a CT brain scan and referral to a paediatrician for assessment of their developmental, general, and endocrinological status.

The authors are grateful to Dr Mary King, paediatric neurologist, for her comments.

1 Frisen L, Holmegaard L. Spectrum of optic nerve hypoplasia. Br 7 Ophthalmol 1978; 62: 7-15.

2 Mosier MA, Lieberman MF, Green R, Knox DL. Hypoplasia of the optic nerve. Arch Ophthalmol 1978; 96: 1437-42.

3 Fielder AR, Levene MI, Trounce JQ, Tanner MS. Optic nerve hypoplasia in infancy. $\mathcal{F} R$ Soc Med 1986; 79: 25-9.

4 Hoyt WF, Kaplan SL, Grumbach MM, Glaser JS. Septooptico dysplasia and pituitary dwarfism. Lancet 1970; ii: $893-4$
5 Ouvier R, Billson F. Optic nerve hypoplasia: a review. $\mathcal{f}$ Child Neurol 1986; 1: 181-8.

6 Taylor D. Congenital tumours of the anterior visual system with dysplasia of the optic discs. Br f Ophthalmol 1982; 66: with dysp 63 .

7 Lambert SR, Hoyt CS, Narahara MH. Optic nerve hypoplasia. Surv Ophthalmol 1987; 32: 1-9.

8 Rogers GL, Brown D, Gray I, Bremer D. Bilateral optic nerve hypoplasia associated with cerebral atrophy. $\mathcal{F}$ Pediat Ophthalmol Strabismus 1981; 18: 18-22.

9 Greenfield PS, Wilcox LM, Weiter J, Adelman L. Hypoplasia of the optic nerve in association with porencephaly. F Pediat Ophthalmol Strabismus 1980; 17: 175-80.

10 Patel H, Tze WJ, Crichton JU, McCormick AQ, Robinson GC, Dolman CL. Optic nerve hypoplasia with hypopituitarism. Am 7 Dis Child 1975; 129: 175-80.

11 West J, Burke JP, Strachan I. Carbamazepine, epilepsy, and optic nerve hypoplasia. Br f Ophthalmol 1990; 74: 511 .

12 Zeki SM, Dutton GN. Optic nerve hypoplasia in children. Br f Ophthalmol 1990; 74: 300-4

13 Tan KL, Tan R, Tan SH, Tan AM. The twin transfusion syndrome. Clinical observations on 35 affected pairs. Clin Pediatr (Phila) 1979; 18: 111-4.

14 Apple DJ, Robb MF, Walsh PM. Congenital anomalies of the optic disc. Surv Ophthalmol 1982;27: 3-41.

15 Alvarez E, Wakakura $M$, Khan $Z$, Dutton GN. The discmacula distance to disc diameter ratio: a new test for confirming optic nerve hypoplasia in young children. $\Im$ Pediatr Ophthalmol Strabismus 1988; 25: 151-4.

16 Sprague JB, Wilson WB. Electrophysiologic findings in bilateral optic nerve hypoplasia. Arch Ophthalmol 1981; 99. 1028-9.

17 Novakovic P, Taylor DS, Hoyt WF. Localising patterns of optic nerve hypoplasia. Brf Ophthalmol 1988; 72: 176-82.

18 Skarf B, Hoyt CS. Optic nerve hypoplasia in children. Association with anomalies of the endocrine and CNS. Arch Ophthalmol 1984; 102: 62-7.

19 Margalith D, Jan JE, McCormick AQ, Tze WJ, Lapointe J. Clinical spectrum of congenital optic nerve hypoplasia Review of 51 patients. Dev Med Child Neurol 1984; 26: 311 22.

20 Edwards WC, Layden WE. Optic nerve hypoplasia. $A m \mathcal{J}$ Ophthalmol 1970; 70: 950-9.

21 Walton DS, Robb RM. Optic nerve hypoplasia. A report of 20 cases. Arch Ophthalmol 1970; 84: 572-8.

22 Acers TE. Optic nerve hypoplasia. Septo-optico-dysplasia syndrome. Trans Am Ophthalmol Soc 1981; 79: 429-57.

23 Brown DR, Milley JR, Riperi UZ, Biglan AW. Retinopathy of prematurity, risk factors in a five year cohort of critically ill prematurity, risk factors in a five year cohort of critic

$24 \mathrm{Ng} \mathrm{YK}$, Fielder AR, Levene MI, Trounce JQ, McLellan N. Are severe acute retinopathy of prematurity and severe periventricular leucomalacia both ischaemic insults? $\mathrm{Br} \mathcal{F}$ Ophthalmol 1989; 73: 111-4.

$25 \mathrm{Ng} \mathrm{YK}$, Fielder AR, Shaw DE, Levene MI. Acute retinopathy of prematurity: risk factors. Arch Dis Child 1988; 63: 693-4

26 Rakic P, Yakolev PI. Development of the corpus callosum and cavum septi in man. F Diary Science 1968; 132: 45-72.

27 Hittner HM, Desmond MM, Montgomery JR. Optic nerve manifestations of human congenital cytomegalovirus infection. Am $\mathcal{F}$ Ophthalmol 1976; 81: 661-5.

28 Ghose S. Optic nerve changes in hydrocephalus. Trans Ophthalmol Soc UK 1983; 103: 217-20.

29 Keltner JL. The disc that really isn't (hypoplastic disc syndrome). Surv Ophthalmol 1985; 29: 349-54.

30 Tamura EE, Hoyt CS. Oculomotor consequences of intraventricular haemorrhages in premature infants. Arch Ophthalmol 1987; 105: 533-5.

31 Benirschke $\mathrm{K}$. Twin placenta in perinatal mortality. NY State f Med 1961; 61: 1499-508.

32 Melnick M. Brain damage in survivor after death of monozygotic co-twin. Lancet 1977; ii: 1287.

33 Roberts-Harry J, Green SH, Willshaw HE. Optic nerve hypoplasia: associations and management. Arch Dis Child 1990; 65: 103-6. 